\title{
Ocorrência de tuberculose em bovinos abatidos no matadouro municipal de Patos - PB - Brasil
}

\section{Ocurrence of the tuberculosis in bovines killeds in the Patos municipal slaughter house - Paraíba - Brazil}

\author{
Ivon Macêdo Tabosa, ${ }^{*}$ Verônica Medeiros Trindade, ${ }^{\star}$ Geraldo Magela Gonçalves Vale, ${ }^{\star *}$ Antônio Flávio de Medeiros Dantas, ${ }^{* *}$ \\ Julia Márcia Vieira, ${ }^{\star \star \star}$ Márcia Bersane Araújo de Medeiros, ${ }^{\star \star \star \star}$ Edisio Oliveira de Azevedo, ${ }^{\star \star \star \star \star}$ Márcia Almeida de Melo, ${ }^{\star \star \star \star \star}$ \\ Max Giovanni Andrade, ${ }^{\star \star \star *}$ Suelia Brilhante de Souza, ${ }^{\star \star \star *}$ Lizamarque da Silva Medeiros, ${ }^{\star \star \star \star}$ \\ Rejane Dias Rodrigues, ${ }^{\star \star \star \star}$ Sérgio Davi Xavier ${ }^{\star \star \star \star}$
}

\begin{abstract}
Resumo
A inspeção de animais em matadouros representa um ponto de partida em potencial para o rastreamento e identificação de "focos" de enfermidades. No período de agosto de 1993 a abril de 1994 foram inspecionados 1021 bovinos oriundos da região semi-árida da Paraíba. Destes, 32 animais apresentaram lesões macroscópicas semelhantes a tuberculose, sendo que cinco foram positivas $(0,48 \%)$, quando confirmados pela bacteriologia e/ou histoquímica.
\end{abstract}

Palavras-chave: tuberculose bovina; M. bovis; matadouro.

\begin{abstract}
The inspection of animals in slaughter house represents a potential start point for the. tracement and identification of focus of diseases between August 1993 and April 1994 there were inspectioned 1021 bovines from the semi-arid region of Paraiba state, Brazil. Thirty-two these animals showed macroscopics lesions similary to tuberculosis, being five of them positive $(0,48 \%)$, whem confirmed by histoquimic and bacteriocal test.
\end{abstract}

Keywords: tuberculosis bovine; M. bovis; slaughter house.

\section{Introdução}

Dentre as doenças infecto-contagiosas, a tuberculose destaca-se pelo seu caráter zoonótico. É uma enfermidade já há muitos anos conhecida e constatada pelos Órgãos de Saúde e Inspeção Animal. Apesar disso, no Brasil existem poucas ações de controle efetivas e nenhum programa nacional em desenvolvimento para erradicá-la.

Na América Latina, na maioria dos países, não se conhece qual é o impacto da infecção humana pelo Mycobacterium bovis, já que as provas se limitam a exames histopatológicos, não permitindo diferenciar este de outros Mycobacterium (OPS/OMS, 1993).

$\mathrm{Na}$ América do Sul, as taxas referentes a condenação de bovinos com lesões de tuberculose em matadouros são muito variáveis, estando na dependência da adoção de programas de controle desta enfermidade (OMS/OPS,1993).

No Brasil, que tem um rebanho estimado em mais de 135 milhões de cabeças, a prevalência de tuberculose bovina em rebanhos testados em quatro regiões do país através da tuberculinização no ano de 1986 oscilou em torno de 0,9 a 2,9\% (Centro Pan-Americano de Zoonoses, 1991).

Os locais onde os animais e/ou seus produtos são manipulados, a exemplo dos matadouros, são pontos estratégicos para obtenção de informações sobre a incidência das enfermidades, assim como permite a identificação da procedência/origem destas (Schenk, Schenk, 1982 ; Ricceti et al., 1989).

Este trabalho teve como objetivo verificar a ocorrência da tuberculose bovina através de estudos de lesões em carcaças e órgãos viscerais de animais abatidos no matadouro municipal de Patos-PB, e oferecer informações desta enfermidade aos órgãos de saúde pública do Estado.

\section{Material e métodos}

Foram inspecionados os principais órgãos (pulmões, fígado, baço, útero e rins), a cadeia linfática mediastínica e mesentérica e carcaças de 1021 bovinos abatidos no matadouro municipal de Patos-PB, no período de agosto de 1993 a abril de 1994. Dos animais que apresentaram lesões

* Professores da UFPB - Patos, PB - Cx. Postal 64 - Fone: (83) 421-3397.

** Bolsistas PIBIC/CNPq.

*** Bolsista da PROEX - UFPB.

**** Alunos de graduação em Medicina Veterinária - UFPB.

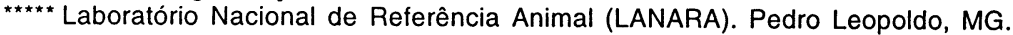


macroscopicamente semelhantes à tuberculose foram colhidas amostras, divididas em duas frações, sendo uma acondicionada sob refrigeração e outra fixada em formol salina a $10 \%$, cortados a $5 \mathrm{~m}$ e corados pelas técnicas hematoxilina-eosina (HE), Fite-Faraco e impregnação pela prata de Gomori. Nas duas últimas técnicas foram usadas lâminas-controle para tuberculose e fungos, respectivamente.

As frações refrigeradas foram transportadas ao laboratório e armazenadas a $-20^{\circ} \mathrm{C}$ para posterior processamento bacteriológico. $\mathrm{O}$ cultivo e isolamento ${ }^{1}$ foi realizado em meios Lowenstein-Jensen e Stonebrink a partir dos espécimes que apresentaram diagnóstico histopatológico positivo para tuberculose.

\section{Resultados e discussão}

Dos animais inspecionados, 32 apresentaram lesões macroscopicamente semelhantes à tuberculose. Mas, à microscopia, apenas cinco apresentavam nódulos, caracterizados por acúmulos focais de macrófagos, células epitelióides, células gigantes de Langhans e área central necrótica com calcificação, e negativa para fungo, caracterizando um granuloma tuberculóide típico. As demais possuíam etiologias distintas (Tabela 1).

Tabela 1: Estudo histopatológico de 32 lesões similares macroscopicamente e identificadas como de tuberculose em bovinos abatidos em Patos-PB entre agosto/1993 a abril/1994

\begin{tabular}{lcc}
\hline Diagnóstico histopatológico & $N^{0}$ de casos & $\%$ \\
\hline Tuberculose $^{\text {a }}$ & 3 & 9,38 \\
Granuloma tuberculóide $^{b}$ & 2 & 6,25 \\
\hline SUBTOTAL & 5 & \\
Granuloma actinomicóide & 2 & 6,25 \\
Abscessos & 8 & 25,00 \\
Granuloma parasitário & 5 & 15,63 \\
Neoplasia & 2 & 6,25 \\
Broncopneumonia & 8 & 25,00 \\
Linfadenite crônica & 2. & 6,25 \\
TOTAL DE CASOS & 32 & 100,00 \\
\hline
\end{tabular}

a) Lesão tuberculóide com presença de bacilo álcool-ácido-resistente (BAAR).

b) Granuloma semelhante, porem sem observado BAAR.

\section{Referências bibliográficas}

ANDRADE, G. B., RIET-CORREA, F., MIELKE, P. V. et al. Estudos histológicos e isolamento de micobactérias de lesões similares à tuberculose em bovinos no Rio Grande do Sul. Pesq. Vet. Bras.v. 11, n. 3/4, p. 81-86, 1991.

CORNER, L.A., MELVILLE, L., McCUBBIN, K. et al. Efficiency of inspecttion procedures for the detection of tuberculous lesions in cattle. Aus. Vet. J., v. 67, n. 11, 1990.

CORNER, L.A. Post mortem diagnosis of Mycobacterium bovis infection in cattle. Vet. Microb., v. 40, p. 53-63, 1994.

CENTRO PANAMERICANO DEZOONOSES (OPS/OMS). Boletines Informativos de Tuberculosis Bovina. v. I, III y.IV (1974, 1977 y 1978).

ERRICO, F., PERDOMO, E., BERMUDEZ, J. etal. Estudio de lesiones similares a tuberculose en bovino del Uruguay. Vet:; v. 2, p. 21-24, 1980.
Dos cinco espécimes com granuloma típico, foram isolados Mycobacterium em duas amostras, sendo uma identificada como $M$. bovis. Já pela técnica histoquímica de Fite-Faraco, três apresentaram bacilo álcool-ácido resistente.

A ausência do bacilo em lesões características de tuberculose examinadas histologicamente já foi registrada, tanto em tecidos com cultura positiva, como negativa para tuberculose, indicando, assim, a pequena quantidade de bacilos na lesão (Andrade et al., 1991). Sendo assim, no município de Patos$\mathrm{PB}$ registra-se a ocorrência de tuberculose em bovinos abatidos em um percentual de $0,48 \%$.

O grau de percepção das lesões macroscópicas na sala de matança depende do exame minucioso de todos os órgãos, acrescendo ainda o exame da cadeia linfática através de cortes seriados (Corner, 1994).

Das lesões macroscopicamente semelhantes à tuberculose, $84 \%$ e $93 \%$ foram negativas nas provas histopatológicas e bacteriológicas, respectivamente. No primeiro caso, provavelmente ocorreu por dois fatores: a falta de observação detaIhada da cadeia linfática, permitindo, assim, que pequenas lesões passem despercebidas (Corner, 1994), e as lesões, mesmo de outras etiologias, possuem características macroscópicas indiferenciáveis da tuberculose (Errico et al., 1980 ; Kantor et al., 1981).

Os países da América do Sul têm percentuais bastante diferenciados com relação à condenação e descarte de órgãos bovinos durante o abate, variando entre $0,008 \%$ no Uruguai até $4,1 \%$ na Argentina, passando pelo Brasil, com um percentual de $0,15 \%$ (OMS/OPAS, 1993). Em termos de Brasil, o percentual verificado em Patos- $\mathrm{PB}$, de $0,48 \%$, ainda é preocupante, principalmente quando inexistem políticas de controle e combate à tuberculose. Por outro lado, é possível que este percentual possa ser bem maior, se considerarmos que o procedimento de inspeção durante o abate pode atingir uma margem de erro de até $47 \%$ (Corner et al., 1990). Neste trabalho, apesar da utilização de exames bacteriológicos, sugere-se o uso de técnicas histopatológicas para o diagnóstico presuntivo da tuberculose em determinadas regiões do Brasil, indicando a situação geral do rebanho, sem considerar, neste contexto, um amplo programa nacional de erradicação.

KANTOR, I. N., DE LA VEGA, E., CABALLERO, P. et al. Estudio de órganos bovinos decomisados por tuberculose, mataderos del gran Buenos Aires. Rev. Med. Vet., v. 62, n. 4, p. 282-285, 1981.

ORGANIZACIÓN PANAMERICANADELASALUD (OPS/OMS). Plan de acción para la erradicación de la tuberculosis bovina en las Américas. Fase I, março, 1993.

RICCETTI, R. V., VASCONCELOS, S. A., ITO, F. et al. A. Investigacão epidemiológica sobre as zoonoses de maior constatação em matadouros. II. Bovinos. Rev. Fac. Med. Vet. Zoot. Univ. S. Paulo, v. 26, n. 1, p. 61-68, 1989.

SCHENK, M. A. M., SCHENK, J. A. Prevalência da tuberculose, cisticercose e hidatidose em bovinos abatidos nos matadouros frigoríficos do Estado do Mato Grosso do Sul, Brasil (1974/79). Comunicado Técnico № 11, p. 1-5. 1982; Empresa Brasileira de Pesquisa Agropecuária - EMBRAPA.

\footnotetext{
${ }^{1}$ Lanara - Pedro Leopoldo, MG.
} 